University of Nebraska - Lincoln

DigitalCommons@University of Nebraska - Lincoln

Mammalogy Papers: University of Nebraska

State Museum

Museum, University of Nebraska State

2-18-1983

\title{
Quantification of Competition among Coexisting Heteromyids in the Southwest
}

Cliff A. Lemen

University of Nebraska-Lincoln, clemen2@unl.edu

Patricia W. Freeman

University of Nebraska-Lincoln, pfreeman1@unl.edu

Follow this and additional works at: https://digitalcommons.unl.edu/museummammalogy

Part of the Zoology Commons

Lemen, Cliff A. and Freeman, Patricia W., "Quantification of Competition among Coexisting Heteromyids in the Southwest" (1983). Mammalogy Papers: University of Nebraska State Museum. 20.

https://digitalcommons.unl.edu/museummammalogy/20

This Article is brought to you for free and open access by the Museum, University of Nebraska State at DigitalCommons@University of Nebraska - Lincoln. It has been accepted for inclusion in Mammalogy Papers: University of Nebraska State Museum by an authorized administrator of DigitalCommons@University of Nebraska Lincoln. 


\title{
QUANTIFICATION OF COMPETITION AMONG COEXISTING HETEROMYIDS IN THE SOUTHWEST
}

\author{
Cliff Lemen and Patricia Waring Freeman
}

\begin{abstract}
Three trapping grids, $225 \mathrm{~m}$ on a side, where established in the desert of southern New Mexico. On grid 1 all Dipodomys (Heteromyidae, Rodentia) were removed; on grid 2 all Perognathus (Heteromyidae, Rodentia) were removed; and on grid 3 no rodents were removed. All grids were censused at two-week intervals for six weeks. When the larger Dipodomys $(40 \mathrm{~g})$ were removed, the Perognathus ( $15 \mathrm{~g}$ ) population increased 2.56-fold (from 27 to 69 individuals) in two weeks. Removal of Perognathus had no effect on numbers of Dipodomys. Our data allow us to estimate the magnitude of the competition between Dipodomys and Perognathus.
\end{abstract}

About 45 species of heteromyid rodents inhabit the southwestern deserts of North America. Most of these taxa belong to the genera Dipodomys (kangaroo rats) and Perognathus (pocket mice). All are nocturnal, burrowing, largely granivorous rodents with cheek pouches. At localities of greatest diversity, four or five species live syntopically (Brown, 1975).

Coexistence in these ecologically similar rodents offers the opportunity to test a basic tenet of competition theory: to what extent can competing species coexist (Volterra, 1928; Gause, 1934; Levins, 1968; MacArthur and Levins, 1968; May, 1973)? In response to this question, much of the research on heteromyids has centered on quantification of methods of niche separation among syntopic species (Brown, 1975; Lemen and Rosenzweig, 1978; Wondolleck, 1978; Price, 1978).

Relatively few studies (Munger and Brown, 1981; Schroder and Rosenzwig, 1975) actually try to measure competition directly. Schroder and Rosenzweig (1975) removed rodents from large study plots with the surprising result that little competition exists between two coexisting species of similar size. They concluded that competition had been important in the past, but is not presently affecting interspecific interactions. Munger and Brown (1981) demonstrated the existence of competition in coexisting desert rodents by documenting an increase in the density of small rodents, Perognathus $(7-17 \mathrm{~g})$, Reithrodontomys $(1 \mathrm{~g})$ and Peromyscus $(17 \mathrm{~g})$, in response to the removal of Dipodomys $(40 \mathrm{~g})$. However, this increase in the density of Perognathus took place only after Dipodomys has been kept off experimental plots for 8 months.

We have concentrated on short-term effects of density perturbations. Schroder and Rosenzweig (1975) found it difficult to lower a species' density because after removing most individuals from an experimental grid other individuals of that same species took their places, often within two weeks. This might indicate an intraspecific mechanism for adjusting local population density that worked very quickly. Our goal was to determine if there is a corresponding short-term mechanism acting intergenerically as well. Here we report an additional experiment to determine the effects of removal on population densities of coexisting heteromyids. 
METhoDs.-The study area was located about $4 \mathrm{~km}$ west of El Paso, Texas in New Mexico, and was trapped during June, July, and August of 1979. Mesquite hummocks dominated the region, and three plots, all of a similar vegetation type, were set out about $1.5 \mathrm{~km}$ apart. Each plot consisted of a $16 \times 16$ grid of trap stations at $15 \mathrm{~m}$ intervals (5.1 ha with 256 traps). Sherman folding live traps $(7.5 \times 23 \mathrm{~cm})$ were used.

The species of heteromyids trapped included Dipodomys ordii, D. merriami, Perognathus penicillatus, and P. flavescens. Perognathus flavescens represented only $2 \%$ of all Perognathus caught. Numbers of the two Dipodomys were nearly equal. We pooled species into Dipodomys or Perognathus corresponding to medium and small heteromyids. Other rodents trapped included Neotoma albigula and Onychomys leucogaster, but together they made up only $4 \%$ of the total trap success. Neither of these cricetids responded to the removal experiments.

Each study plot was censused every two weeks with two nights of trapping. The traps were baited with wild bird seed, and the same amout of seed was placed at the trap stations of the control grid. All heteromyids trapped were weighed, sexed, and individually ear-tagged or toeclipped. After each census a Lincoln index was used to estimate rodent densities. The average trap success for all census preiods was $24 \%$, indicating that trap competition was minimal. The difference between the Lincoln index density estimate for a plot and the total number of different indi. viduals trapped was small, averaging 2.1 animals per species. These two facts indicated that our techniques provided reasonable estimates of rodent densities.

One grid served as a control (no removals), another as a Dipodomys removal, and the third, a Perognathus removal. Rodents were removed during the first two weeks of the study. The two removal grids were trapped approximately every 3 days during this two-week period using a grid of one-half normal trap density. After the first two weeks no more animals were removed and all plots were censused at two-week intervals to study the changes in the rodent populations.

Census periods for the control grid were as follows: census period $1=$ July $9-10$; period $2=$ July 27-28; period $3=$ August 8-9; and period $4=$ August 26-27. On the Perognathus removal grid the census peirods were: period $1=$ July $6-7$; period $2=$ July $25-26$; period $3=$ August $12-13$; and period $4=$ August 24-25. The census periods for the Dipodomys removal plot were: period $1=$ July 4-5; period $2=$ July 23-24; period $3=$ August 10-11; and period $4=$ August 22-24.

Results. - Estimates of the number of rodents on our grids are shown in Fig. 1. Confidence limits on estimates (Table 1) were calculated following Pielou (1974, p. 124-5). Our removal technique significantly lowered rodent densities on the experimental plots. On the Dipodomys removal plot numbers of Dipodomys were decreased by $51 \%$, while only a $27 \%$ decrease in Perognathus occurred on the Perognathus removal plot. In both cases these new densitiies were significanlty lower than initial densities $(P<0.05$; for Dipodomys removals $\mathrm{t}=3.58$; for Perognathus removals $\mathrm{t}=2.34$; using confidence limits discussed above).

To test the effect of rodent removals, we compared rodent numbers on the control plot with those on the experimental plots. Numbers of both Dipodomys and Perognathus increased on the control plot in the first two weeks of the experiment. Chi-square tests were performed for both experimental plots using the change in rodent numbers on the control plot as a standard for the numbers on the experimental plots. On the Perognathus removal plot there was no difference in the number of Dipodomys as compared to the control plot $\left(\chi^{2}=0.003, \mathrm{df}=1, P<0.05\right)$. In fact, there is a remarkable similarity in the number of Dipodomys on the control and Perognathus removal grids througout the experiment (Fig. 1).

The census data from the Dipodomys removal plot show a different pattern. There is a significant increase in the number of Perognathus as compared to the control plot $\left(\chi^{2}=4.05\right.$, df $\left.=1, P<0.05\right)$. The number of Perognathus on this grid increased by a factor of 2.56 in two weeks (Table 1). 

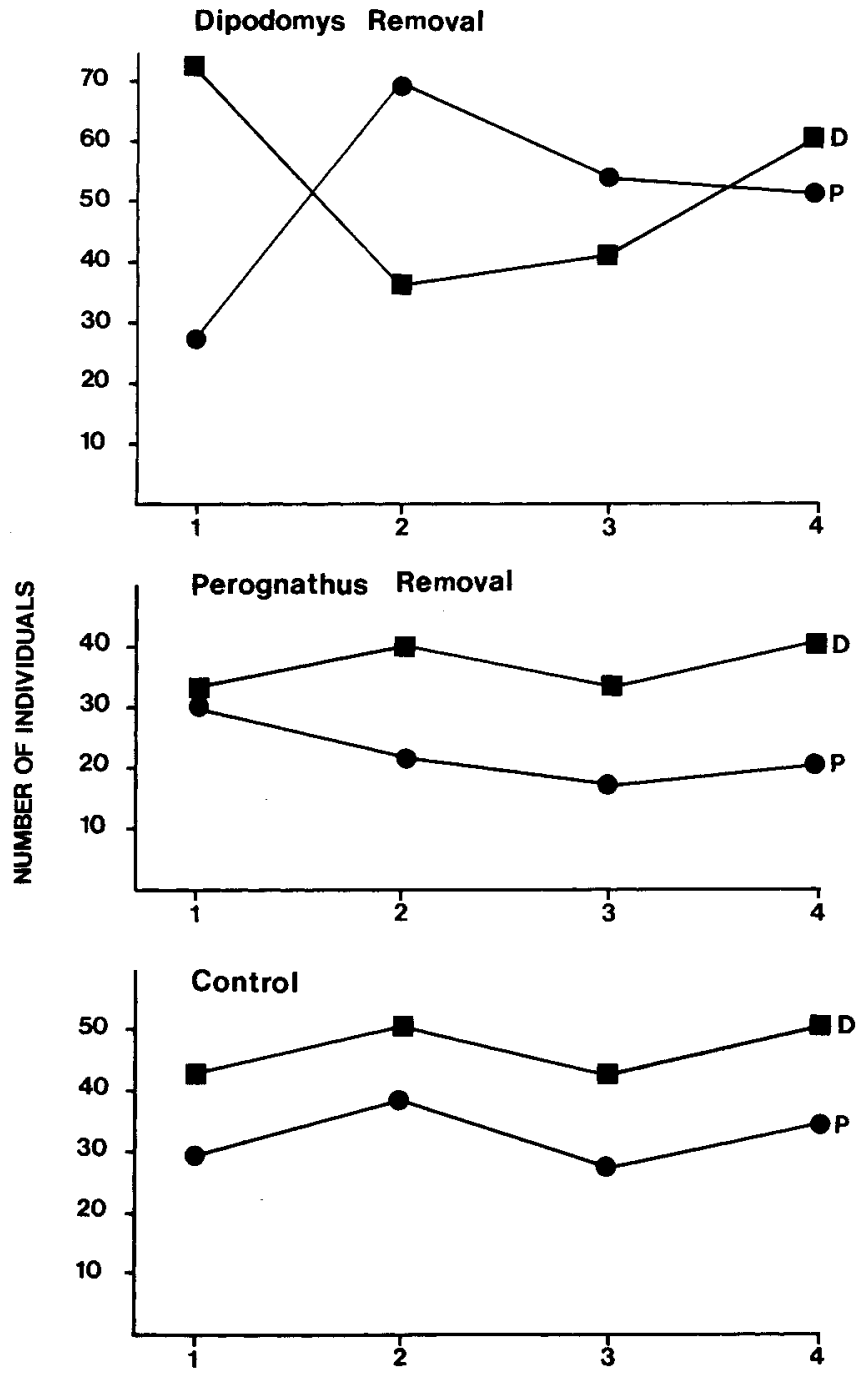

CENSUS PERIODS

Fig. 1.-Estimated numbers of Dipodomys (D) and Perognathus (P) on the three trapping grids. Refer to Methods for exact dates of census periods.

From census period 2 to 4 on the Dipodomys removal plot, the recovery of Dipodomys toward their original number was matched with a similar decrease in the number of Perognathus. The general inverse relationship between Dipodomys numbers and Perognathus numbers on this plot is shown in Fig. 2. The regression is significant $(P<0.05)$ with a negative slope of -0.93 . This slope is an estimate of the short-term competitive effect of Dipodomys on Perognathus. For every one Dipodomys removed their are 
TABLE 1.-Estimates of rodent population sizes ( \pm 2 standard deviations) in the first two census periods on the three study plots.

\begin{tabular}{lccccc}
\hline & \multicolumn{2}{c}{ CENSUS \#1 } & & \multicolumn{2}{c}{ CENSUS \#2 } \\
\cline { 2 - 3 } \cline { 5 - 6 } & Perognathus & Dipodomys & & Perognathus & Dipodomys \\
\hline Control plot & $29.3 \pm 5.1$ & $42.9 \pm 8.9$ & & $38.5 \pm 1.5$ & $50.7 \pm 3.1$ \\
Perognathus removal plot & $30.0 \pm 3.6$ & $33.3 \pm 2.8$ & & $21.8 \pm 3.4$ & $40.1 \pm 0.7$ \\
Dipodomys removal plot & $27.1 \pm 2.8$ & $60.5 \pm 4.3$ & & $66.7 \pm 4.0$ & $36.0 \pm 9.4$ \\
\hline
\end{tabular}

0.93 more Perognathus expected on the grid. This estimate is possible because we altered the number of Dipodomys and measured the response in the number of the Perognathus. We are assuming all other factors that might also change the density of Perognathus, such as food resource levels or habitat structure, were constant through the two weeks of the removal. Therefore, any change in the number of Perognathus is attributable to the removal of Dipodomys. The stability of the number of Perognathus on the control grid supports our assumption that without Dipodomys removal, the number of Perognathus on the grids would have remained nearly constant. On the Perognathus removal plot there was no significant relationship between number of Perognathus and Dipodomys, indicating that the removal of Perognathus had no effect on the number of Dipodomys.

On the Dipodomys removal plot, where large numbers of both $D$. ordii and $D$. merriami were removed, the ratio of the number of these two species

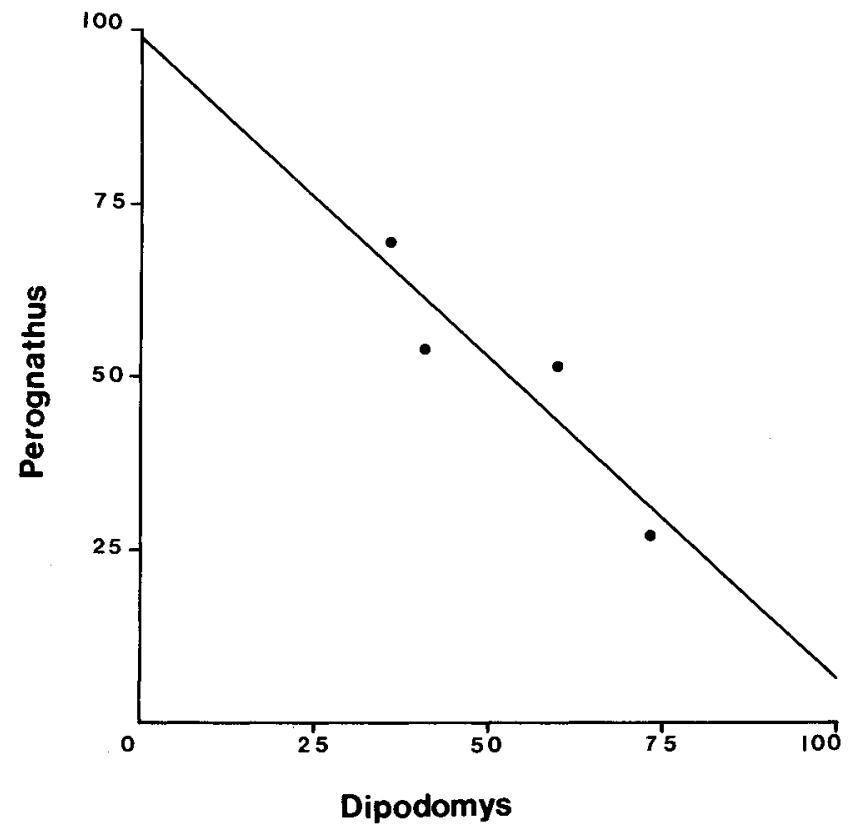

FIG. 2.-The regression of the number of Perognathus (Y) on the number of Dipodomys (X) on the Dipodomys removal plot for all 4 census periods, $y=98.9-0.93 \mathrm{x}, P$ slope is zero $<0.05$. Exact dates of census periods are in the Methods section. 


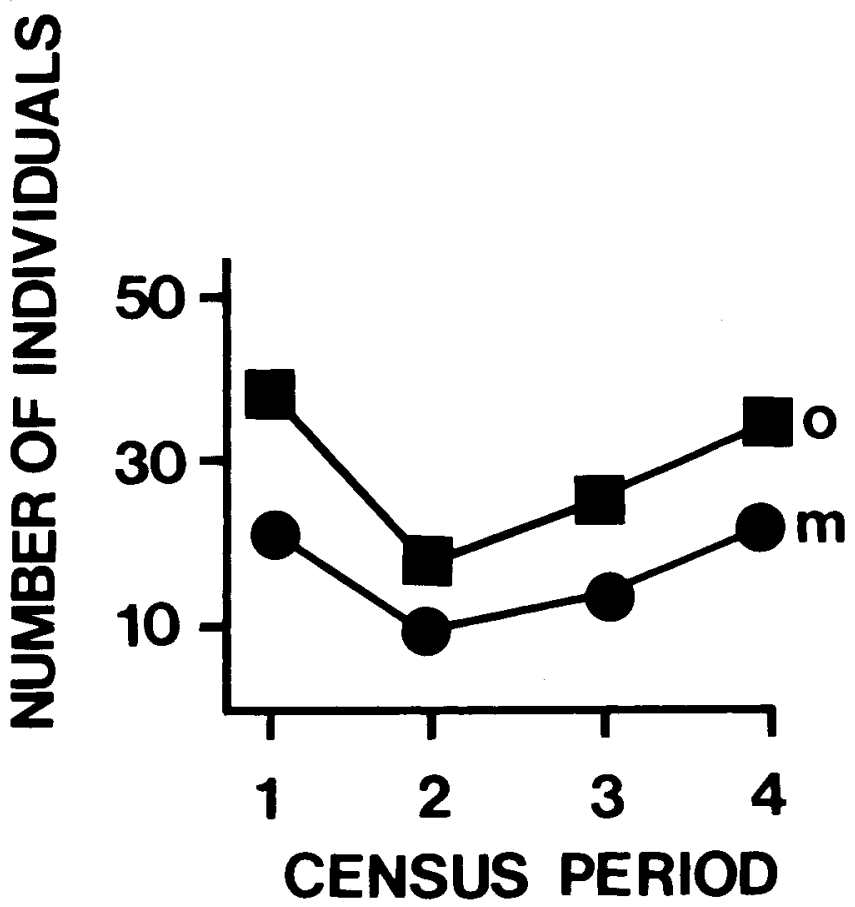

FIG. 3.-Estimated densities of D. ordii $(o)$ and D. merriami $(\mathrm{m})$ on the Dipodomys removal plot for all 4 census periods. Exact dates of census periods are in the Methods section.

remained nearly constant throughout the recovery phase of the experiment (Fig. 3).

Discussion.-Our findings offer evidence that these heteromyids are competing. The competitive nature of the interaction was suggested by increase in the number of Perognathus in response to removal of Dipodomys. This result is contrary to that found by Schroder and Rosenzweig (1975) who found no density response between two species of Dipodomys of very similar size. In addition, the quick increase of the number of Perognathus to the removal of Dipodomys differs from the findings of Munger and Brown (1981) were it took 8 months for the small rodents to increase in number in response to the removal of Dipodomys.

One point not yet considered is the mechanism of the competition between Dipodomys and Perognathus. The 8-month lag found by Munger and Brown (1981) might indicate resource-mediated competition. It may have taken that long for the resource levels to come to a new equilibrium in response to removal of Dipodomys. Conversely, direct interference may also be important in competition among heteromyids (O'Farrell, 1980) as has been shown in other rodent assemblages (Grant, 1972). Our results are consistent with the hypothesis of interference competition through aggressive interactions for two reasons. First, the density adjustment of Perognathus was too quick for food resource levels to change. Second, the number of 
Perognathus was effected by removal of large rodents, but not vice versa. This is consistent with the speculation that large body size would be an advantage if aggressive interactions are mediating this interaction.

We wish to thank R. Smartt and M. Smartt for their aid on this project. Our work was supported by funds from the Field Museum of Natural History. S. Derr-Bruner at the Field Museum and Gail Littrell at the University of Nebraska State Museum typed drafts of the manuscripts.

\section{Literature Cited}

Brown, J. H. 1975. Geographical ecology of desert rodents. In Ecology and evolution of communities (M.L. Cody and J.M Diamond, eds.). Belknap Press, New Haven.

Gause, G. F. 1934. The struggle for existence. Wiliams and Wilkins, Baltimore.

Grant, P. R. 1972. Interspecific competition among rodents. Ann. Rev. Ecol. Syst., 3:79-106.

Lemen, C. A., and M. L. Rosenzweig. 1978. Microhabitat selection in two species of heteromyid rodents. Oecologia, 33:127-135.

Levins, R. 1968. Evolution in changing evironments. Princeton University Press, Princeton.

Mac Arthur, R. H., And R. Levins. 1967. The limiting similarity, convergence, and divergence of coexisting species. Amer. Nat., 101:377-385.

MAY, R. H. 1973. Stability and complexity in model ecosystems. Princeton University Press, Princeton.

Munger, J. C., and J. H. Brown. 1981. Competition in desert rodents: an experiment with serni-permeable exclosures. Science, 21 1:510-512.

O' FarReLL, M. J. 1980. Spatial relationships of rodents in a sagebrush community. J. Mamm., 61:589-605.

Pielou, E. C. 1974. Population and community ecology. Gordon and Breach Science Publishers, New York.

Price, M. V. 1978. The role of microhabitat in structuring desert rodent communities. Ecology, 59:910-921.

Schroder, G. E., And M. L. Rosenzweig. 1975. Perturbation analysis of competition and overlap in habitat utilizations between $D$. ordii and D. merriami. Oecologia, 19:9-28.

Volterra, V. 1928. Variations and fluctuations of the number of individuals in animals species living together. In Animal ecology (R. Chapman, ed.) McGraw-Hill, New York.

Wondolleck, J. T. 1978. Forage area separation and overlap in heteromyid rodents. J. Mamm., 59:510-518.

Address of authors: Dept, of Zoology, Field Museum of Natural History, Chicago, IL 60605 Current addresses: CL, School of Life Sciences, PFW, Univ. of Nebraska State Museum, Univ. of Nebraska, Lincoln, NE 68588) 